\title{
Malignant Fibrous Histiocytoma of the Ankle: A Case Report
}

\author{
by Katherine Neiderer, DPM, MPH ${ }^{1} ₫$, Jodi Walters, DPM, James Dancho, DPM, FACFAS, Margaret \\ Rennels, MD
}

The Foot and Ankle Online Journal 5 (3): 1

Malignant fibrous histiocytomas are a rare soft tissue sarcoma that present as indolent tumors in adults. Treatment consists of wide surgical excision. Local recurrence and metastasis is common and patients must be followed for such. We describe the case of a 49 year-old male that presented with a painless "lump" on the front of his ankle. Magnetic resonance imaging showed a $2.6 \times 3.5 \times 4.3 \mathrm{~cm}$ lesion that displayed high intensity on the T2 weighted image. The mass partially encased the tibialis anterior tendon along the medial aspect without invading the body of the tendon. The radiologist suspected a possible malignant neoplasm including synovial sarcoma or giant cell tumor of the tendon sheath. The patient underwent wide excision of the lesion and pathology diagnosed it as malignant fibrous histiocytoma at the anterior ankle. The patient underwent limb sparing surgery without adjuvant chemotherapy and after 2 years of follow-up he has had no recurrence or metastasis.

Key words: Ankle, histiocytoma, malignant fibrous, neoplasms, sarcoma

Accepted: February, $2012 \quad$ Published: March, 2012

This is an Open Access article distributed under the terms of the Creative Commons Attribution License. It permits unrestricted use, distribution, and reproduction in any medium, provided the original work is properly cited. (The Foot and Ankle Online Journal (www.faoj.org), 2012 All rights reserved.

$\mathrm{M}$ alignant fibrous histiocytomas (MFH) are the most common soft tissue sarcomas in adults. $^{1,2}$ MFH is a rare sarcoma that has no predilection for age and affects both genders equally. In a recent major review of 458 soft tissue sarcomas $11 \%$ were in the thigh (the most common location) while 3\% were in a distal extremity, either distal to the knee or elbow. ${ }^{3}$ Prognosis is correlated to tumor size, depth and location and has been discovered along with gouty tophi and internal fixation..$^{4-7}$

Address correspondence to: Katherine Neiderer, DPM,MPH

Email: Katherine.Neiderer@va.gov

1 Southern AZ VA Health Care System, 3601 S. 6th Ave. (2-112) Tucson, AZ 85723
MFH most commonly metastasizes to the lungs and patients should be followed with regular chest radiographs. Recurrence most commonly occurs within 2 years. $^{3} \quad$ The treatment consists of primary resection with adjuvant chemotherapy depending on clear margins, depth and lymph node involvement. ${ }^{8}$

\section{Case Report}

A 49 year-old gentleman presented to our clinic with a complaint of a "bump" of the anterior medial ankle. The patient noted only minimal discomfort with high topped shoes or work type boots, as they would press directly on the lesion and cause irritation. 


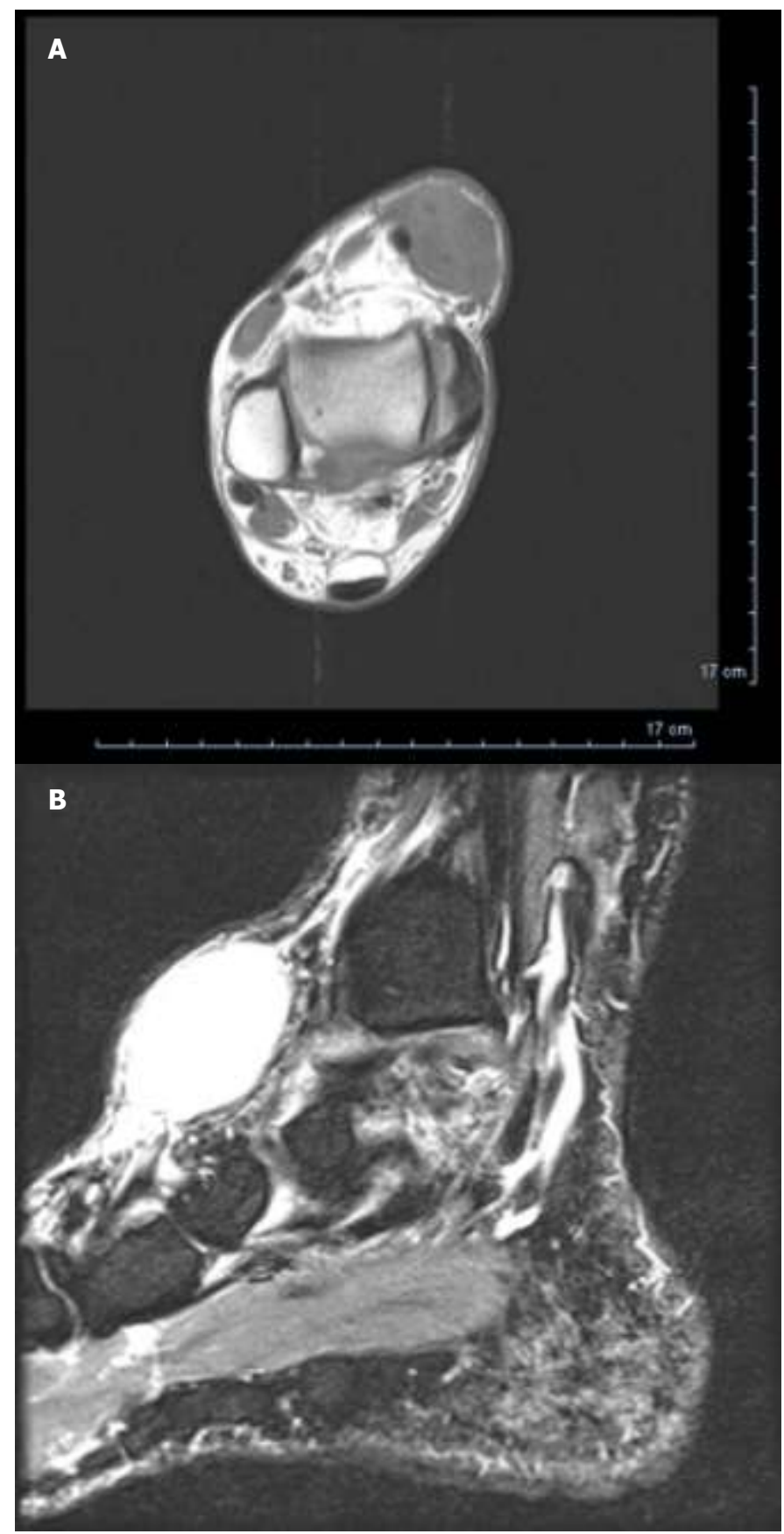

Figure 1 Magnetic resonance image of the soft tissue sarcoma. (A) Axial view (B) Longitudinal view.

The lesion had been present for at least one year, and was progressively growing over the past few months. No history of trauma to the area was noted and he had no previous treatment for the lesion.
The medical history was significant for hypertension, sleep apnea and chronic back pain. He had previous umbilical and inguinal hernia repair, a knee arthroscopy and mucocele removal. He denied any other lesions, similar to the one on his foot, anywhere on his body.

On physical examination, there was a round, mildly fluctuant, rubbery golf-ball sized lesion measuring approximately $3.5 \mathrm{~cm}$ in diameter along the lateral aspect of the tibialis anterior tendon. The lesion was fairly mobile underneath the skin and transillumination was not possible. It was fairly painless to palpation, leading to the suspicion that the mass was merely irritated by rubbing, or direct pressure from shoegear. There was no surrounding erythema, edema, ulceration or telangiectasias associated with the lesion.

Dorsalis pedis and posterior tibial pulses were palpable and capillary filling time was instantaneous to all digits bilaterally. Tinel's sign was not elicited on percussion of the mass and sharp-dull, light touch and vibratory sensation were intact. Manual muscle testing was within normal limits and the lesion was noted to translocate with dorsiflexion and plantar flexion of the ankle.

Plain films revealed a large soft tissue rounded density anteriorly and medially overlying the right ankle without any definitive underlying bony abnormality. The patient was then sent for magnetic resonance imaging (MRI) to determine the characteristics of the lesion. The lesion measured $2.6 \times 3.5 \times 4.3 \mathrm{~cm}$ and displayed high signal intensity and intense enhancement on the T2 weighted image. (Fig. 1) The mass partially encased the tibialis anterior tendon along the medial aspect without invading the body of the tendon. The radiologist suspected a possible malignant neoplasm due to the intense enhancement and size with differential diagnoses including synovial sarcoma or giant cell tumor of the tendon sheath.

Due to the suspicious nature of the lesion and for surgical planning a core needle biopsy was performed to obtain a clearer diagnosis. 


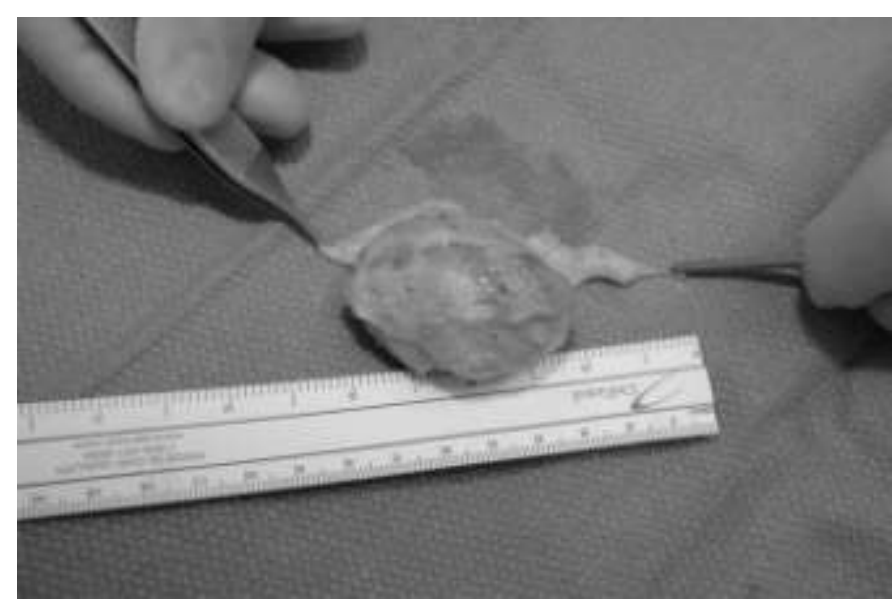

Figure 2 Gross specimen of soft tissue sarcoma. Although it appeared to be encapsulated, it was not entirely circumscribed and included a transected margin with mitotically active pleomorphic cells.

It revealed a relatively cellular sample containing a few somewhat atypical cells with moderate mitotic activity and simple excision was performed. The patient was taken to the operating room and a linear incision was made over the underlying lesion. The lesion was dissected free of the surrounding soft tissue and appeared to be part of the medial branch of the superficial peroneal nerve. The lesion was a yellow/tan color and seemed well encapsulated. The tumor was easily separated from the surrounding tissues, but we were unable to remove it from the nerve, so the nerve had to be sacrificed. The final specimen measured $4.8 \times 4.0 \times 2.8 \mathrm{~cm}$. (Fig. 2 )

Gross examination showed slight lobulation of the lesion with focal hemorrhage and no sign of necrosis. Sectioning the specimen revealed a soft, yellow/tan, vaguely lobulated mass with broad, fine, and indiscrete, fibrous septae. Microscopic examination noted an extremely cellular tumor with pleomorphic, mitotically active cells with a mitotic rate of 9 per high powered field with a histologic grade of 3 . It was also noted at this time that despite the apparent encapsulation of the tumor, there was transection of the tumor margin and aggressive mitosis in the area that suggested a malignant fibrous histiocytoma of high grade malignancy. (Fig. 3)

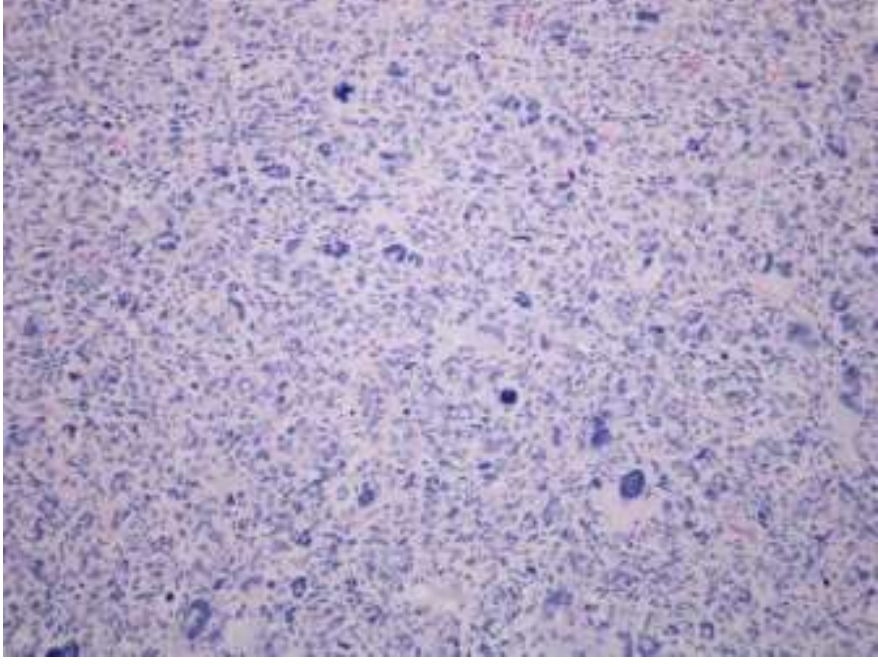

Figure 3 Histological assessment reveals an area of pleomorphic tumor with bizarre giant cells and very high mitotic rate including abnormal mitoses (10x power/hematoxylin and eosin stain)

Due to the malignant finding and the incomplete margin a surgical oncologist was consulted. The patient returned to the operating room where a wide local excision of the area was performed. The resected tissue was examined, and no further remnants of the lesion were seen at the margins. A full thickness skin graft of the area was taken from the patient's thigh and subsequently placed on the wound bed. The patient was kept non-weight bearing in an off-loading boot and subsequent local wound care was performed until complete healing was achieved.

Approximately 5 months later the patient developed a firm, well-demarcated lesion directly adjacent to the previous surgical margin. An MRI revealed a $5.1 \mathrm{x}$ $4.5 \times 4.0 \mathrm{~mm}$ mass just superficial but abutting the extensor digitorum longus tendons. This lesion was intermediate on T1 and increased on T2, showing a relatively homogenous enhancement. Due to its small nature it was difficult to differentiate between the vessels in the vicinity. Because of the patients' history he was taken back to the operating room. A $5 \mathrm{~cm}$ linear incision was made over the mass. The incision was deepened to the level of the superficial peroneal nerve where the mass was visualized within the nerve's fibers. 
It was traced proximally and distally and the entire nerve and lesion were removed in toto. Further inspection of the area revealed no additional lesions. Pathologic exam identified the $1.2 \times 0.9 \times 0.3 \mathrm{~cm}$ specimen as a traumatic neuroma of the intermediate branch of the superficial peroneal nerve.

The patient is currently being followed for another pea-sized lesion that was discovered 3 months after his second surgery. It is approximately $2 \mathrm{~mm}$ in diameter, is movable and lies just proximal to the second surgical margin along the course of the superficial peroneal nerve. We are following him for any growth in this lesion and do not have any current plans for further surgical intervention.

Due to both of his surgeries the patient has numbness to the dorsum of his foot. He has no residual weakness to any of the muscle groups to his foot and has noticed no other lesions anywhere else on his body, with exception to the foot. The patient has also had serial chest radiographs that have shown no metastases.

\section{Discussion}

Malignant fibrous histiocytoma (MFH), first described in the sixties, is the most common soft tissue sarcoma in adults. It occurs most often in the proximal portions of the extremities including the thigh and buttocks. ${ }^{1}$ The mean age is 55.8 with a range of 18 to 84 years and equally affects males and females. Most patients present with an asymptomatic tumor that they have noticed in less than a year. ${ }^{3}$

Initial diagnosis is frequently attained by biopsy and MRI is useful in surgical planning. This requires sampling from several areas of the tumor as the histological sample can vary from location to location. There is no specific immunohistochemical marker for $\mathrm{MFH}$, so the diagnosis is usually one of exclusion. ${ }^{8}$ MFH are classified using immunohistochemical methods for type and grade according to the system of Enzinger and Weiss with the lower grades signifying level of differentiation. ${ }^{2}$
The histology of $\mathrm{MFH}$ is variable and several subtypes including storiform-pleomorphic, myxoid, giant cell and inflammatory exist with the storiformpleomorphic being the most common. ${ }^{9} \quad$ All variants may be locally aggressive and surgical excision is required.

Resection achieving tumor-free margins of at least 1$1.5 \mathrm{~cm}$ is the goal for every case and has been shown to be the strongest risk factor of local recurrence. ${ }^{8}$ For patients without clear margins, further surgical resection is preferred before using other treatment modalities. ${ }^{10}$ Local recurrence has reported to range from 31-38\%, with $73-100 \%$ occurring within 24 months. ${ }^{3,8}$ Postoperative radiation therapy has been shown to decrease local recurrence rate although it has also been associated with increased morbidity due to difficulty in wound healing. ${ }^{11-13}$

Metastasis is a significant concern in patients diagnosed with MFH. Peiper, et al., found of 458 patients 29 developed metastases after a median of 12 months, with the most common, $80 \%$, seeding to the lungs. Prognostic risk factors for distant metastases include tumor size, depth and grade (based on the classification of Enzinger and Weiss). The annual risk of distant metastases was 3.5 times higher in patients with higher grade tumors. ${ }^{3}$

Peiper, et al., recommends chemotherapy to those patients with synchronous pulmonary or regional lymph node metastases after resection of the primary tumor. After 6 courses of chemotherapy, resection of the pulmonary lesion was then performed. Even with aggressive resection and adjuvant chemotherapy, cumulative 5 -year survival rates are $65 \%-80 \%{ }^{8,14,15}$

In conclusion, although $\mathrm{MFH}$ is the most common soft tissue sarcoma in adults, it is still a rare diagnosis especially in the distal extremity. In 24 months of follow-up our patient had an additional lesion diagnosed as a traumatic neuroma although approximately $30 \%$ of patients will have a second MFH. ${ }^{3}$ He has had no evidence of metastasis to this date and is monitored every 3 months with a physical exam and chest radiograph. 


\section{References}

1. Enjoji M, Hashimoto H, Tsuneyoshi M, Iwasaki H. Malignant fibrous histiocytoma. A clinicopathologic study of 130 cases. Acta Pathol Jpn 1980 30:727-741. [PubMed]

2. Enzinger F, Weiss S. Soft Tissue Tumors. 4th Ed St. Louis, Mosby, 2001. Website]

3. Peiper M, Zurakowski D, Knoefel W'T, Izbicki JR. Malignant fibrous histiocytoma of the extremities and trunk: An institutional review. Surgery 2004 135: 59-66. PubMed]

4. Richter H, Vinh TN, Mizel MS, Temple HT. Malignant fibrous histiocytoma associated with remote internal fixation of an ankle fracture. Foot Ankle Int 2006 27: 375-379. [PubMed]

5. Carnero S, Teran P, Trillo E. Malignant fibrous histiocytoma arising in a gouty tophus at the second metacarpophalangeal joint. J Plast Reconstr Aesthet Surg 2006 59:775-778.

6. Gibbs JF, Huang PP, Lee RJ, et al. Malignant fibrous histiocytoma: an institutional review. Cancer Invest 19: 2003 2327, 2001. [PubMed]

7. Le Doussal V, Coindre JM, Leroux AHacene K, Terrier P, Bui NB, Bonichon F, Collin F, Mandard AM, Contesso G. Prognostic factors for patients with localized primary malignant fibrous histiocytoma: a multicenter study of 216 patients with multivariate analysis. Cancer 1996 77:1823-1830. [PubMed]

8. Issakov J, Kollender Y, Soyfer V, Bickels J, Flusser G, Meller I, Merimsky O. A single-team experience of limb sparing approach in adults with high-grade malignant fibrous histiocytoma. Oncol Rep 2005 14:1071-1076. [PubMed]

9. Fletcher C, Unni, KK and Mertens, F. World Health Organization Classification of Tumours. Pathology and genetics of tumours of soft tissue and bone. Lyon, IARC Press, 2002.[Website]

10. Pezzi CM, Rawlings MS, Jr., Esgro JJ, Pollock RE, Romsdahl MM. Prognostic factors in 227 patients with malignant fibrous histiocytoma. Cancer 1992 69: 2098-2103. PubMed]

11. Bujko K, Suit HD, Springfield DS, Convery K. Wound healing after preoperative radiation for sarcoma of soft tissues. Surg Gynecol Obstet 1993 176:124-134. [PubMed]

12. Sadoski C, Suit HD, Rosenberg A, Mankin H, Efird J. Preoperative radiation, surgical margins, and local control of extremity sarcomas of soft tissues. J Surg Oncol 1993 52: 223230. PubMed]

13. Spiro IJ, Rosenberg AE, Springfield D, Suit H. Combined surgery and radiation therapy for limb preservation in soft tissue sarcoma of the extremity: the Massachusetts General Hospital experience. Cancer Invest 1993 13: 86-95. [PubMed]

14. Bramwell VH. Current perspectives in the management of soft-tissue sarcoma. The role of chemotherapy in multimodality therapy. Can J Surg 1988 31: 390-396. PubMed]

15. Engellau J. Prognostic factors in soft tissue sarcoma. Tissue microarray for immunostaining, the importance of whole-tumor sections and time-dependence. Acta Orthop Scand 2004 5(Suppl): 2 p preceding table of contents-52, backcover. PubMed] 